\title{
Efficacy and Safety of Enoxaparin for Prophylaxis of Postoperative Venous Thromboembolism After Esophagectomy: A Single-center Prospective Randomized Controlled Phase II Study
}

\author{
YOSHIHIRO TANAKA ${ }^{1}$, ATSUKO YAMADA ${ }^{2}$, SHINYA HIRATA ${ }^{3}$, \\ HIDEHARU TANAKA ${ }^{1}$, TAKUJI SAKURATANI ${ }^{4}$, NOBUHISA MATSUHASHI ${ }^{1}$, \\ KAZUYA YAMAGUCHI ${ }^{1}$, TOSHIO SHIMOKAWA ${ }^{5}$ and KAZUHIRO YOSHIDA ${ }^{1}$ \\ ${ }^{1}$ Department of Surgical Oncology, Graduate School of Medicine, Gifu University, Gifu, Japan; \\ ${ }^{2}$ Department of Surgery, Gifu Prefecture General Hospital, Gifu, Japan; \\ ${ }^{3}$ Department of Surgery, Ibi Kousei Hospital, Gifu, Japan; \\ ${ }^{4}$ Department of Surgery, Gifu Municipal Hospital, Gifu, Japan; \\ ${ }^{5}$ Department of Medical Data Science, Graduate School of Medicine, \\ Wakayama Medical University, Wakayama, Japan
}

\begin{abstract}
Background/Aim: This study aimed to assess whether low-molecular-weight heparin (LMWH) is effective and safe in preventing postoperative venous thromboembolism (VTE) in patients undergoing esophageal cancer surgery. Patients and Methods: In this single-institution, prospective, randomized trial, 73 patients with esophageal cancer undergoing esophagectomy were randomly divided into the enoxaparin group (E group) and intermittent pneumatic compression group (I group). The primary endpoint was efficacy of enoxaparin, and secondary endpoints were evidence of bleeding and serum anti-Xa activity in the E group. Results: The E group comprised 42 patients and the I group comprised 31 patients. Deep vein thrombosis was observed in $0(0 \%)$ patients in the E group and $7(22.6 \%)$ patients in the I group $(p=0.002)$. Soluble fibrin monomer complex was significantly lower in the Eversus I group on day $8(p<0.001)$. D-dimer was significantly lower in the Eversus I group on days 2, 8, and 15 ( $p=0.008, p<0.001, p<0.001$, respectively). Conclusion: VTE was significantly reduced by using enoxaparin.
\end{abstract}

This article is freely accessible online.

Correspondence to: Yoshihiro Tanaka, MD, Ph.D., Department of Surgical Oncology, Graduate School of Medicine, Gifu University, 1-1 Yanagido, Gifu 501-1194, Japan. Tel: +81 0582306000, Fax: +810582301074, e-mail: yoshihirotana11@hotmail.com

Key Words: Perioperative prophylaxis, enoxaparin, venous thromboembolism, esophageal surgery, anti-Xa activity.
Venous thromboembolism (VTE) is the second leading cause of death in cancer patients receiving outpatient chemotherapy (1). As represented by Trousseau's syndrome, multiple pathophysiologic mechanisms contribute to the hypercoagulability associated with cancer (2). The Japan VTE Treatment Registry revealed the maximal risk factor for VTE to be cancer (3). Major surgery for cancer located in the abdomen or chest is associated with a high incidence of VTE, as the major postoperative complication, including deep venous thrombosis (DVT) and pulmonary thromboembolism (PTE) (4). According to previous reports, the incidence of symptomatic VTE after esophagectomy is reported to range from 2.9 to $3.8 \%,(5,6)$, whereas that of asymptomatic VTE after esophagectomy ranges from 5.9 to $23.3 \%$ (7-9). Thus, the prevalence of asymptomatic VTE is not small after esophageal cancer surgery, and occasionally, unfortunate outcomes can occur; thus, prevention of VTE is very important.

The use of low-molecular-weight heparin (LMWH) was recommended to prevent VTE after cancer surgery (10). Lee et al. reported that in patients with cancer and acute VTE, LMWH was more effective than an oral anticoagulant in reducing the risk of recurrent VTE, without increasing the risk of bleeding (11). However, an optimal strategy of thromboprophylaxis for esophagectomy has not been formulated, and to the best of our knowledge, there are no reports comparing the effects of LMWH through randomized controlled trials (RCTs).

Enoxaparin is a LMWH that functions as an anticoagulant agent by forming a complex with antithrombin 3 (AT-III) and promoting AT-III activity. The evidence for enoxaparin in orthopedic, gynecologic malignancy and abdominal or pelvic malignancy has already been established (12-14). In 
gastrointestinal surgery, prevention of VTE only in patients undergoing abdominal surgery has become an indication for health insurance reimbursement. So, we planned to evaluate the effectiveness and safety of enoxaparin for esophageal resection involving cervical and chest surgery, in addition to abdominal surgery, in a phase II study. Additionally, no prospective RCTs are available combining esophagectomy with enoxaparin use and measurement of serum anti-Xa activity.

Thus, we designed a single-institution, prospective, phase II RCT to confirm the efficacy and safety of using enoxaparin for prophylaxis of VTE after esophagectomy. Importantly, we conducted DVT screening using venous ultrasonography (US) and PTE and iliac vein thrombosis screening using contrastenhanced computed tomography (CT) 4 weeks after surgery.

\section{Patients and Methods}

Eligibility criteria. This single-center, double-arm, prospective RCT was conducted with patients who underwent elective esophagectomy for thoracic esophageal cancer in the Department of Surgical Oncology of the Gifu University. Patients who were $>18$ years of age at the time of registration and who had histologically or cytologically confirmed Stage IB-IV esophageal squamous cell carcinoma were included in the present study. The other inclusion criteria were an Eastern Cooperative Oncology Group performance status of $0-1$; a life expectancy of $>12$ weeks; and adequate liver, bone marrow, renal, and cardiovascular functions (serum bilirubin $\leq 1.5 \mathrm{mg} / \mathrm{dl}$; neutrophil count $\geq 1,500 / \mathrm{mm}^{3}$; serum aspartate aminotransferase and alanine aminotransferase levels $\leq$ twice the upper limit of normal range; platelet count $\geq 10 \times 10^{4} / \mathrm{mm}^{3}$; hemoglobin $\geq 8.0 \mathrm{~g} / \mathrm{dl}$; creatinine $\leq 1.2 \mathrm{mg} / \mathrm{dl}$ [or creatinine clearance $\geq 30 \mathrm{ml} / \mathrm{min}]$ and platelet count $>10 \times 10^{4} / 1$. Patients who had previously received anticoagulants for VTE or non-valvular atrial fibrillation or had hypersensitivity to heparin, heparin-induced thrombocytopenia, impaired renal function (creatinine clearance $<30 \mathrm{ml} / \mathrm{min}$ ), a recent history of hemorrhagic disease with intracranial bleeding, previously received spinal or ophthalmologic operation, or preoperatively prolonged prothrombin time (PT) or activated partial thromboplastin time (APTT) were excluded from this study. The other exclusion criteria were serious concomitant illness, symptomatic infectious disease, severe allergy, peripheral neuropathy, and uncontrolled diabetes mellitus. Patients satisfying the inclusion criteria were registered among continuous esophageal cancer surgical cases during the period from April 2014 to December 2017.

Ethical considerations. This trial was conducted in accordance with the World Medical Association Declaration of Helsinki and was registered with the University Hospital Medical Information Network Clinical Trials Registry (Registration number: UMIN000014623). This trial was approved by the Ethics Committee of Gifu University (Approval number 26-16), and written informed consent was obtained from all patients.

Treatment strategy. We classified tumor stage according to the Union for International Cancer Control (UICC) tumor-nodemetastasis (TNM) staging, version 7 (15). Routine esophagoscopy, esophagography, and positron emission tomography CT or contrastenhanced CT were performed to establish the clinical stage of tumors. For patients in clinical stage IB-IIIC, neoadjuvant chemotherapy and stage IV, induction chemotherapy was planned to be performed before surgery.

A three-incision esophagectomy with two- or three-field lymphadenectomy was performed. In particular, patients with lower thoracic main tumor with no supramediastinal and supraclavicular lymph node swelling at first visit underwent two-field lymphadenectomy, whereas those with upper and middle thoracic main tumor underwent three-field lymphadenectomy. Thoracoscopic esophagectomy was commonly performed in cases of clinical tumor stages T1 and T2 at first visit and included cases of shrinkage after neoadjuvant chemotherapy. Open thoracotomy was performed in patients with clinical tumor stage $\mathrm{T} 3$ and in those with the possibility of T4 stage. A 7-cm abdominal skin incision was made by a hand-assisted laparoscopic technique.

All patients were extubated on the day after surgery and started on ambulation. Epidural anesthesia was not performed in all patients, and pain relief was attained by morphine and acetaminophen in the perioperative period. Oral intake was started on postoperative day (POD) 6, and the patients were discharged from hospital approximately 3 weeks after surgery.

Methods of antithrombosis in the two groups. We randomly allocated patients who underwent esophagectomy for esophageal cancer to an intermittent pneumatic compression (IPC) group (I group) or enoxaparin group (E group) in a 1:1 ratio via the envelope method. DVT was screened using venous US in all patients on PODs 2,8 , and 15 by a physician who had experience with more than 400 cases of venography and lower limb echography. PTE and iliac vein thrombosis screening was performed 4 weeks after surgery using contrast-enhanced CT.

IPC was applied in the E group from the start of operation to the first ambulation from bed, and then the patients received subcutaneous injection of enoxaparin (Kaken Pharmaceutical. Co., LTD., Japan, 2000 IU) at 18:00 on POD 1 after confirmation of no bleeding from the operative site and then twice daily on PODs 2-14. For patients with a creatinine clearance of 30 to $50 \mathrm{ml} / \mathrm{min}$ or those weighing less than 40 $\mathrm{kg}$, the administration frequency of enoxaparin was reduced to once per day. In contrast, IPC in the I group was applied from the start of operation to the first ambulation from bed.

Study endpoints. We investigated the effectiveness and safety of enoxaparin in preventing postoperative VTE. The primary endpoint of this study was efficacy as evidenced by the incidence of VTE (including DVT and PTE) after surgery. In cases where thrombosis was observed in a lower limb before surgery, exacerbations after surgery or VTE appearing in other locations were included in the incidence of VTE. Secondary endpoints were related to safety: the incidence of all enoxaparin treatment-related adverse events including postoperative major bleeding, clinically relevant nonmajor bleeding, perioperative transition of coagulation system parameters such as soluble fibrin monomer complex (S-FMC), Ddimer, PT, APTT, and the relationship between serum anti-Xa activity and the color of chest tube drainage in the E group patients who consented to measurement of their serum anti-Xa activity.

Assessment. Checks of lower limb vein thrombosis by US were performed before surgery and on PODs 2,8 , and 15 . In case of symptoms suspicious for PTE, contrast-enhanced CT was performed to confirm the presence or absence of thrombus in the pulmonary arteries. We routinely checked the pulmonary arteries and the inferior 
Tanaka et al: The Efficacy and Safety of Thromboprophylaxis With Enoxaparin for Esophageal Surgery

vena cava from the common iliac vein via contrast-enhanced $\mathrm{CT}$, and DVT via US at 1 month after surgery in all patients. S-FMC, Ddimer, hemoglobin and PT (\%), PT (sec), and APTT (sec) were measured in all patients on PODs 2, 8, and 15. D-dimer was measured with STA-R Evolution (Roche Diagnostics Co., Ltd. Tokyo, Japan) using Nanopia ${ }^{\circledR}$ D-dimer (Sekisui Medical Co., Ltd. Tokyo, Japan; standard value $\leq 1.0 \mu \mathrm{g} / \mathrm{ml}$ ). A ProSound SSD-5500 US system (Aloka Co., Ltd. Tokyo, Japan) was used for the US examinations.

Definition of adverse events. The following definitions were used to evaluate safety. Major enoxaparin-related bleeding was defined as 1) death due to bleeding, 2) reoperation required due to hemorrhage (including reoperation for subcutaneous major hematoma), 3) hemoglobin decrease of $\geq 2 \mathrm{~g} / \mathrm{dl}$ after POD 2 compared with that on POD 1, 4) blood transfusion of $\geq 400 \mathrm{ml}$ performed during the observation period, 5) bleeding from important organs (intracranial, digestive tract, subconjunctival) during the observation period, 6) extension of the scheduled hospitalization period due to bleeding, or 7) drainage volume exceeding $100 \mathrm{ml} / \mathrm{h}$ per bleeding episode from the chest drain. Minor enoxaparin related bleeding was defined as 1) bloody change in the color of chest drainage when the outflow rate is $<100 \mathrm{ml} / \mathrm{h}, 2$ ) skin purpura, 3) nasal hemorrhage, 4) hematuria unrelated to urinary catheterization, or 5) wound bleeding without the need to discontinue enoxaparin. Other adverse events were graded in accordance with the US National Cancer Institute-Common Terminology Criteria for Adverse Events version 4.0 (16).

Statistical analysis. According to the report by Sakon et al. (17), the incidence of VTE in Japanese patients undergoing major abdominal surgery is $24.7 \%$, whereas in a clinical trial with patients with enoxaparin undergoing curative abdominal or pelvic cancer surgery, the incidence of VTE was $1.2 \%$ (14). Given that our study targeted the same race, it is assumed that almost the same rate of thrombus inhibition would be obtained unless cervical and thoracic surgery were added to abdominal surgery for esophagectomy. Thus, the sample size was calculated at $0.05 \%$ as an alpha error with $80 \%$ detection power. Assuming the dropout rate to be $10 \%$, the number of cases required was 70 cases ( 35 cases each).

Continuous variables are expressed as the mean or median value (standard deviation) and categorical variables are expressed as frequency (percentage). Continuous variables were analyzed by twosample $t$-test with Bonferroni adjustment for multiple comparisons, and categorical variables were analyzed by Fisher's exact test. The median value (interquartile range) and Wilcoxon test (MannWhitney test) were used for unpaired samples. A $p$-value of $<0.05$ was considered to indicate statistical significance. All statistical analyses were performed using $\mathrm{R}$ version 3.5.1 software.

\section{Results}

Seventy-two patients were enrolled of whom 41 comprised the E group and 31 comprised the I group. All 72 patients completed follow up period without drop-out.

Mean patient ages were 67.05 years in the E group and 67.23 years in the I group. The performance status was $0-1$ in 36 patients $(87.8 \%)$ in the E group and $30(96.8 \%)$ in the I group. There was no significant difference in patient background characteristics except for the presence or absence of preoperative chemotherapy (Table I).
Table I. Characteristics of patients.

\begin{tabular}{|c|c|c|c|}
\hline & $\begin{array}{c}\text { Enoxaparin } \\
\text { group*1 } \\
\mathrm{n}=41 \\
\text { No. }(\%)\end{array}$ & $\begin{array}{c}\text { IPC } \\
\text { group* } \\
n=31 \\
\text { No. }(\%)\end{array}$ & $p$-Value** \\
\hline Age (years) & $67.05(7.98)$ & $67.23(7.73)$ & 0.925 \\
\hline \multicolumn{4}{|l|}{ Gender } \\
\hline Male & $33(80.5)$ & $27(87.1)$ & 0.536 \\
\hline Female & $8(19.5)$ & $4(12.9)$ & \\
\hline Hight $(\mathrm{cm})$ & $162.73(7.76)$ & $162.54(7.13)$ & 0.916 \\
\hline Body weight $(\mathrm{Kg})$ & $57.46(8.97)$ & $54.72(9.67)$ & 0.219 \\
\hline Body mass index & $21.70(2.96)$ & $20.68(3.17)$ & 0.167 \\
\hline $\mathrm{CCr}(\mathrm{ml} / \mathrm{min})$ & $86.27(27.77)$ & $97.08(32.10)$ & 0.131 \\
\hline \multicolumn{4}{|l|}{ Perfomance status } \\
\hline 0 & $3(7.3)$ & $6(19.4)$ & 0.184 \\
\hline 1 & $33(80.5)$ & $24(77.4)$ & \\
\hline 2 & $5(12.2)$ & $1(3.2)$ & \\
\hline \multicolumn{4}{|l|}{ Stage } \\
\hline IA & $7(17.1)$ & $11(35.5)$ & 0.175 \\
\hline IB & $1(2.4)$ & $3(9.7)$ & \\
\hline IIA & $1(2.4)$ & $0(0.0)$ & \\
\hline IIB & $5(12.2)$ & $3(9.7)$ & \\
\hline IIIA & $6(14.6)$ & $3(9.7)$ & \\
\hline IIIB & $4(9.8)$ & $1(3.2)$ & \\
\hline IIIC & $12(29.3)$ & $10(32.3)$ & \\
\hline IV & $5(12.2)$ & $0(0.0)$ & \\
\hline \multicolumn{4}{|l|}{ COPD } \\
\hline Yes & $1(2.4)$ & $5(16.7)$ & 0.076 \\
\hline No & $40(97.6)$ & $25(83.3)$ & \\
\hline \multicolumn{4}{|l|}{ Hypertension } \\
\hline Yes & $23(56.1)$ & $17(54.8)$ & 1.000 \\
\hline No & $18(43.9)$ & $14(45.2)$ & \\
\hline \multicolumn{4}{|l|}{ Hyper lipidemia } \\
\hline Yes & $10(24.4)$ & $8(25.8)$ & 1.000 \\
\hline No & $31(75.6)$ & $23(74.2)$ & \\
\hline \multicolumn{4}{|l|}{ Hyperuricemia } \\
\hline Yes & $4(9.8)$ & $2(6.5)$ & 0.693 \\
\hline No & $37(90.2)$ & $29(93.5)$ & \\
\hline \multicolumn{4}{|l|}{ Heart disease } \\
\hline Yes & $4(9.8)$ & $4(12.9)$ & 0.719 \\
\hline No & $37(90.2)$ & $27(87.1)$ & \\
\hline \multicolumn{4}{|l|}{ Diabetes mellitus } \\
\hline Yes & $4(9.8)$ & $6(19.4)$ & 0.310 \\
\hline No & $37(90.2)$ & $25(80.6)$ & \\
\hline \multicolumn{4}{|l|}{$\begin{array}{l}\text { Cerebrovascular } \\
\text { events }\end{array}$} \\
\hline Yes & $7(17.1)$ & $4(12.9)$ & 0.747 \\
\hline No & $34(82.9)$ & $27(87.1)$ & \\
\hline \multicolumn{4}{|l|}{$\begin{array}{l}\text { Neo-adjuvant } \\
\text { chemotherapy }\end{array}$} \\
\hline Yes & $32(78.0)$ & 16 (51.6) & $0.024^{\dagger}$ \\
\hline No & $9(22.0)$ & $15(48.4)$ & \\
\hline
\end{tabular}

IPC: Intermittent pneumatic compression; Ccr: Creatinine clearance; COPD: Chronic obstructive pulmonary disease. *Continuous variable is average (standard deviation), categorical variable is frequency (percentage); **Two-sample $t$-test is used for continuous variables, and Fisher's exact test is used for categorical variables. $\dagger p<0.05$. 
Preoperative laboratory data showed no difference between the E group and I group in coagulation factors and hemoglobin level. Operative procedure, operation time, and amount of bleeding were not significantly different between the two groups (Table II).

Three patients $(7.3 \%)$ in the E group and two $(6.5 \%)$ in the I group had thrombosis in the soleal vein before surgery. Among them, no new thrombosis or exacerbations were observed in the postoperative period.

VTE occurred in 0 patients in the $\mathrm{E}$ group [0.0\%; $95 \%$ confidence interval $(\mathrm{CI})=0.0-8.6)]$ and in 7 patients in the I group $(22.6 \%$; 95\% CI=9.6-41.1) $(p=0.002)$. VTE in the E group was observed in two cases of right soleal vein thrombosis on PODs 8 and 15 , one case of left posterior tibial vein thrombosis on POD 8 , one case of right femoral vein thrombosis on POD 8 , one case of right soleal vein and posterior tibial vein thrombosis on POD 8, and one case of right femoral vein and left soleal vein thrombosis on POD 8. One case of symptomatic PTE on POD 8 was observed that was treated with direct oral anticoagulant. Enhanced CT and US screening performed at 1 month after surgery showed no incidences of VTE, except as aforementioned, nor of iliac vein thrombosis.

Postoperative changes in laboratory parameters (value [95\% CI]) were as follows: the S-FMC level was significantly lower in the E group $v s$. I group on POD $8[-0.80(-2.40,0.00)$ vs. $-5.50(-13.90,-4.00) \mu \mathrm{g} / \mathrm{ml}, p<0.001]$. The D-dimer level was significantly lower in the E group $v s$. I group on POD 2 $[-4.60(-5.30,-3.00) v s .-6.20(-10.15,-4.00) \mu \mathrm{g} / \mathrm{ml}, p=0.006]$, POD $8[-4.20(-5.70,-2.50) v s .-11.00(-20.40,-6.95) \mu \mathrm{g} / \mathrm{ml}$, $p<0.001]$, and on POD $15[-3.50(-5.50,-1.80) v s .-7.60$ $(-12.15,-4.20) \mu \mathrm{g} / \mathrm{ml}, p<0.001]$. There was no significant difference in the change in PT, APTT, and hemoglobin between the two groups (Figure 1, Table III).

Consent to measure serum anti-Xa activity was obtained from $27(65.9 \%)$ patients in the E group. The mean values (standard error) of anti-Xa activity were as follows: 0.418 $(0.080) \mathrm{ng} / \mathrm{ml}$ on POD 2, $0.205(0.038) \mathrm{ng} / \mathrm{ml}$ on POD 8 , and $0.264(0.066) \mathrm{ng} / \mathrm{ml}$ on POD 15 (Figure 2). Among these 27 patients in whom we could investigate the association between anti-Xa activity and the change in chest drainage color, chest drainage had become slightly bloody, indicating minor enoxaparin-related bleeding, in only one patient on POD 2. This patient's serum anti-Xa activity at this point was $0.92 \mathrm{ng} / \mathrm{ml}$. The bleeding was improved only by stopping enoxaparin; neither surgery for hemostasis nor blood transfusion was required. No other major bleeding or adverse events related to enoxaparin were observed in the E group.

Surgery-related morbidities included grade 1 recurrent nerve palsy in 4 patients ( 2 in each group), grade 1 chylothorax in 3 patients ( 2 in the E group, 1 in the I group), and grade 2 pneumonia in 1 patient in the I group. There was no mortality in either group.
Table II. Preoperative Laboratory data and operative findings.

\begin{tabular}{|c|c|c|c|}
\hline $\begin{array}{l}\text { Preoperative } \\
\text { laboratory data }\end{array}$ & $\begin{array}{c}\text { Enoxaparin } \\
\text { group } * 1 \\
(\mathrm{n}=41)\end{array}$ & $\begin{array}{c}\text { IPC } \\
\text { group } * 1 \\
(n=31)\end{array}$ & $p$-Value $* 2$ \\
\hline APTT (sec) & $\begin{array}{c}27.90 \\
{[26.00,28.90]}\end{array}$ & $\begin{array}{c}28.00 \\
{[26.00,29.95]}\end{array}$ & 0.520 \\
\hline D-dimer $(\mu \mathrm{g} / \mathrm{ml})$ & $\begin{array}{c}1.50 \\
{[1.10,1.90]}\end{array}$ & $\begin{array}{c}1.40 \\
{[0.90,1.75]}\end{array}$ & 0.442 \\
\hline Hemoglobin (g/dl) & $\begin{array}{c}11.80 \\
{[10.10,12.60]}\end{array}$ & $\begin{array}{c}11.70 \\
{[10.75,13.40]}\end{array}$ & 0.314 \\
\hline PT $(\%)$ & $\begin{array}{c}105.00 \\
{[100.00,116.00]}\end{array}$ & $\begin{array}{c}110.00 \\
{[100.00,119.50]}\end{array}$ & 0.488 \\
\hline PT (sec) & $\begin{array}{c}12.50 \\
{[12.10,12.90]}\end{array}$ & $\begin{array}{c}12.40 \\
{[12.05,12.85]}\end{array}$ & 0.494 \\
\hline S-FMC $(\mu \mathrm{g} / \mathrm{ml})$ & $\begin{array}{c}3.00 \\
{[3.00,3.90]}\end{array}$ & $\begin{array}{c}3.00 \\
{[3.00,4.10]}\end{array}$ & 0.809 \\
\hline Operative findings & $\begin{array}{c}\text { Enoxaparin } \\
\text { group*3 } \\
(\mathrm{n}=41)\end{array}$ & $\begin{array}{c}\text { IPC } \\
\text { group } * 3 \\
(n=31)\end{array}$ & $p$-Value $* 4$ \\
\hline Time of operation (min) & $\begin{array}{c}518.00 \\
{[350.00,738.00]}\end{array}$ & $\begin{array}{c}489.00 \\
{[392.00,755.00]}\end{array}$ & 0.282 \\
\hline Bleeding (g) & $\begin{array}{c}335.00 \\
{[40.00,2580.00]}\end{array}$ & $\begin{array}{c}335.00 \\
{[40.00,700.00]}\end{array}$ & 0.394 \\
\hline \multicolumn{4}{|l|}{ Procedure } \\
\hline $\begin{array}{l}\text { Open thoracotomy } \\
\text { Thoracoscopic surgery }\end{array}$ & $\begin{array}{l}22(53.7) \\
19(46.3)\end{array}$ & $\begin{array}{l}13(41.9) \\
18(58.1)\end{array}$ & 0.351 \\
\hline
\end{tabular}

APTT: Activated partial thromboplastin time; PT: prothrombin time; SFMC: Soluble fibrin monomer complex. ${ }^{* 1}$ The median (interquartile range); ${ }^{2}$ Wilcoxon test (Mann-Whitney test); ${ }^{3}$ The continuous variable represents the median value (range), and the categorical variable represents the frequency (proportion (\%)); ${ }^{* 4}$ Continuous variables are evaluated by Wilcoxon test (Mann-Whitney test) and categorical variable by Fisher's exact test.

As VTE occurred only in the I group, we analyzed the preoperative risk factors of VTE only in that group. Univariate analysis revealed that age, preoperative APTT, and operation mode showed a tendency to be related to postoperative VTE ( $p=0.078,0.083$, and 0.099 , respectively) (Table IV). Results of multivariate analysis (logistic regression analysis) using covariates with a $p$-value $<0.100$ in the univariate analysis revealed no factors to be significant indicators of postoperative VTE (Table V).

\section{Discussion}

The following findings were obtained from this prospective RCT. First, enoxaparin significantly suppressed the occurrence of VTE in patients with esophageal surgery without any major adverse events. Second, S-FMC and Ddimer values suggested that micro-thrombus may have been suppressed in the E group. Third, of note, the anti-Xa 

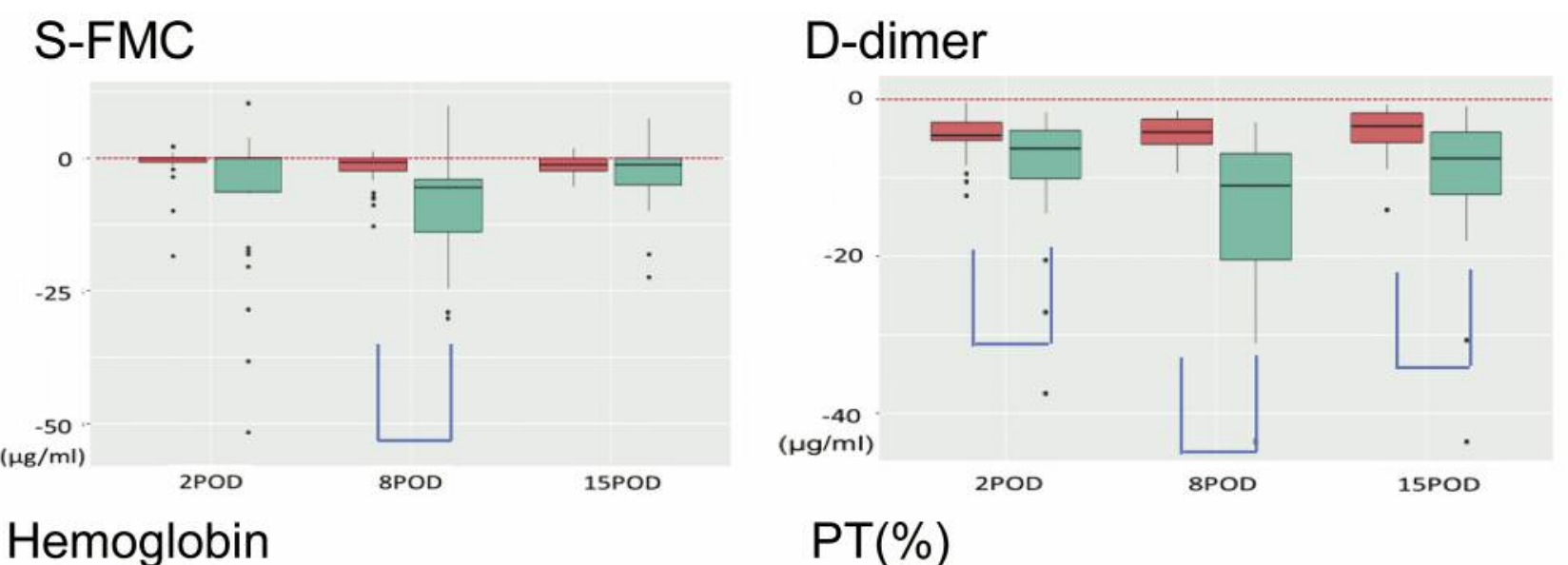

\section{Hemoglobin}

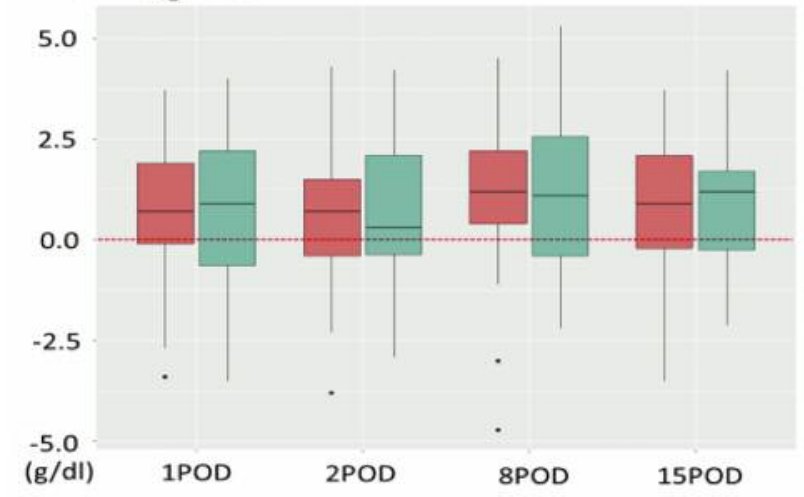

$\mathrm{PT}(\mathrm{sec})$

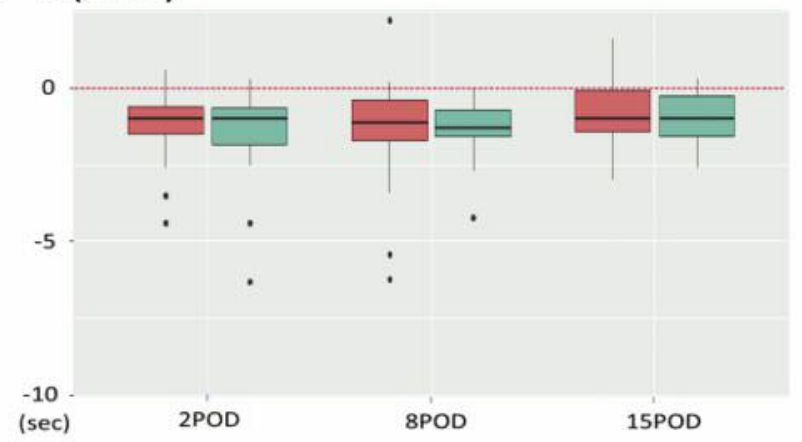

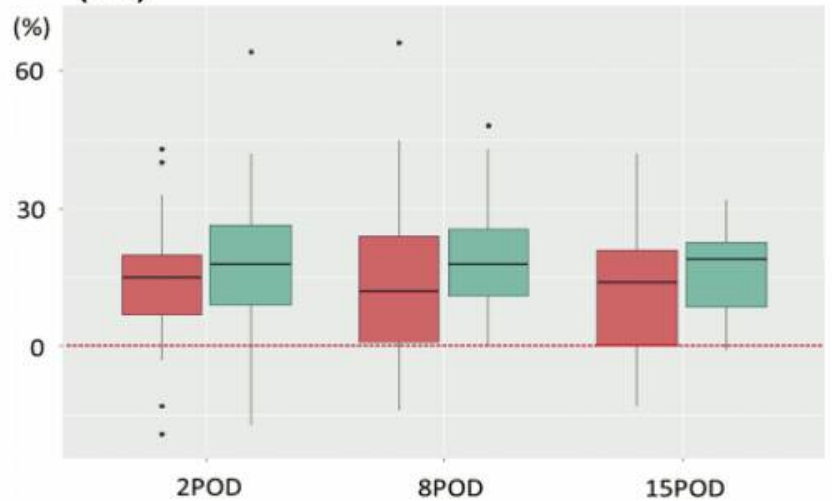

APTT(sec)

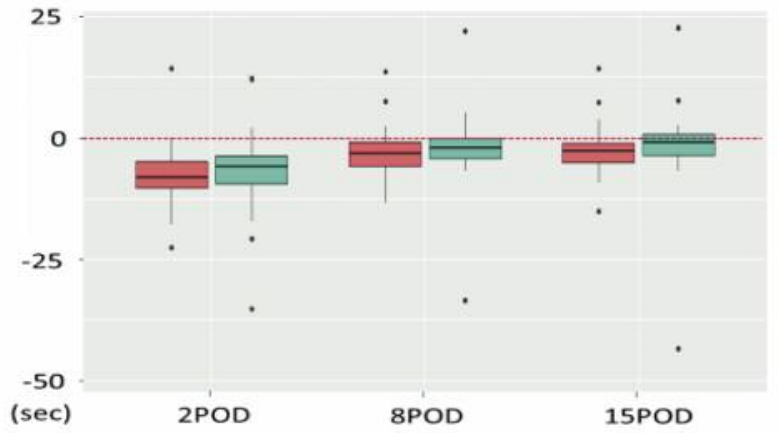

Figure 1. Postoperative parameters [amount of change in examination value: (preoperative value - postoperative value)].

activity tended to be higher in the early postoperative days. Japanese prospective epidemiological findings on the incidence rate of VTE after abdominal laparotomy surgery were reported in 2006. According to this prospective survey, postoperative VTE occurred in $24.7 \%$ (37/150) of patients when operation time for laparotomy of a malignant tumor exceeded $45 \mathrm{~min}$. DVT after abdominal surgery and PTE thereafter were serious postoperative complications that could have a lethal course (17). The results of the present study can be judged to be comparable to previous epidemiological surveys in western countries (11, 18 ), and it is expected that postoperative VTE prevention will become an important part of risk management even in Japan.

According to large-scale studies, the proportion of perioperative asymptomatic DVT treated without anticoagulant 
Table III. Postoperative parameters [amount of change in examination value: (preoperative value - postoperative value)].

\begin{tabular}{|c|c|c|c|c|}
\hline & Enoxaparin $\operatorname{roup}^{*}(\mathrm{n}=41)$ & IPC group $(n=31)^{*}$ & $p$-Value** & adj. $p$-Value*** \\
\hline \multicolumn{5}{|c|}{ S-FMC $(\mu \mathrm{g} / \mathrm{ml})$} \\
\hline 2POD & $-0.10[-0.80,0.00]$ & $0.00[-6.40,0.00]$ & 0.560 & 1.000 \\
\hline 8POD & $-0.80[-2.40,0.00]$ & $-5.50[-13.90,-4.00]$ & $<0.001^{\dagger}$ & $<0.001^{\dagger}$ \\
\hline 15POD & $-1.20[-2.40,0.00]$ & $-1.30[-5.05,0.00]$ & 0.330 & 0.990 \\
\hline \multicolumn{5}{|c|}{ D-dimer $(\mu \mathrm{g} / \mathrm{ml})$} \\
\hline 2POD & $-4.60[-5.30,-3.00]$ & $-6.20[-10.15,-4.00]$ & $0.002^{\dagger}$ & $0.006 \dagger$ \\
\hline $8 \mathrm{POD}$ & $-4.20[-5.70,-2.50]$ & $-11.00[-20.40,-6.95]$ & $<0.001^{\dagger}$ & $<0.001 \dagger$ \\
\hline 15POD & $-3.50[-5.50,-1.80]$ & $-7.60[-12.15,-4.20]$ & $<0.001^{\dagger}$ & $<0.001^{\dagger}$ \\
\hline \multicolumn{5}{|c|}{ Hemoglobin $(\mathrm{g} / \mathrm{dl})$} \\
\hline 1POD & $0.70[-0.10,1.90]$ & $0.90[-0.65,2.20]$ & 0.754 & 1.000 \\
\hline 2POD & $0.70[-0.40,1.50]$ & $0.30[-0.35,2.10]$ & 0.785 & 1.000 \\
\hline $8 \mathrm{POD}$ & $1.20[0.40,2.20]$ & $1.10[-0.40,2.55]$ & 0.720 & 1.000 \\
\hline 15POD & $0.90[-0.20,2.10]$ & $1.20[-0.25,1.70]$ & 0.720 & 1.000 \\
\hline \multicolumn{5}{|l|}{$\mathrm{PT}(\%)$} \\
\hline 2POD & $15.00[7.00,20.00]$ & $18.00[9.00,26.50]$ & 0.181 & 0.543 \\
\hline $8 \mathrm{POD}$ & $12.00[1.00,24.00]$ & $18.00[11.00,25.50]$ & 0.135 & 0.405 \\
\hline 15POD & $14.00[0.00,21.00]$ & $19.00[8.50,22.50]$ & 0.081 & 0.243 \\
\hline \multicolumn{5}{|l|}{$\mathrm{PT}(\mathrm{sec})$} \\
\hline $2 \mathrm{POD}$ & $-1.00[-1.50,-0.60]$ & $-1.00[-1.85,-0.65]$ & 0.542 & 1.000 \\
\hline $8 \mathrm{POD}$ & $-1.10[-1.70,-0.40]$ & $-1.30[-1.60,-0.75]$ & 0.272 & 0.816 \\
\hline 15POD & $-1.00[-1.40,-0.10]$ & $-1.00[-1.60,-0.25]$ & 0.569 & 1.000 \\
\hline \multicolumn{5}{|l|}{ APPT(sec) } \\
\hline 2POD & $-8.00[-10.30,-4.80]$ & $-5.80[-9.45,-3.75]$ & 0.334 & 1.000 \\
\hline 8POD & $-3.10[-5.90,-0.90]$ & $-2.00[-4.10,-0.10]$ & 0.049 & 0.147 \\
\hline 15POD & $-2.50[-5.00,-1.00]$ & $-0.70[-3.60,0.75]$ & 0.042 & 0.126 \\
\hline
\end{tabular}

IPC: Intermittent pneumatic compression; S-FMC: Soluble fibrin monomer complex; PT: prothrombin time; APTT: activated partial thromboplastin time; POD: postoperative day; SEC: second. *Median value (standard deviation); **Wilcoxon test (Mann-Whitney test); ***Adjusted by multiple comparison of Bonferroni; ${ }^{\dagger} p<0.05$.

therapy or with elastic stockings alone ranged from 14.5 to $23.7 \%(17,19)$. Indeed, in the present study, DVT occurred in 6 patients $(19.4 \%)$ in the I group along with one case of PTE. All 6 patients who developed DVT had no symptoms in the lower limbs. There is also a report that the probability of symptomatic DVT is only $23.5 \%$ among all DVT (20). Given the risk of developing PTE, screening for DVT appeared to be insufficient after symptoms appeared.

Walker et al. reported that in a study of the annual transition of VTE expression rates in each group of 83,203 cancer patients and 57,7207 healthy persons extracted from four UK databases, VTE was strongly linked to cancer (21). Postoperative VTE is known to occur frequently following esophagectomy (8). The Japan VTE Treatment Registry (JAVA study) indicated that the greatest risk for VTE was found to be cancer (3). In particular, the presence of cancer increases the risk of developing VTE by 4 to 7 times $(22,23)$, and Gallus et al. reported that the risk of developing lethal PTE in cancer patients who underwent surgery tripled compared with noncancer patients who underwent similar surgery (24). In particular, cancer patients often have multiple risk factors for VTE in addition to cancer itself, and various researches are being conducted on anticancer drugs, central venous catheters, long-term bed-ridden living, and underlying diseases as risk factors (22-25). In a study prospectively examining VTE incidence in 2373 cancer surgery patients in Italy, age ( $>60$ years), past history of VTE, anesthesia time ( $>2 \mathrm{~h}$ ), cancer stage, and time in bed ( $>4$ days) were recognized as risk factors for the occurrence of VTE, and with such risk factors, the odds ratio (OR) of onset of VTE was 2.6 to 6.0 (26). To clarify the independent risk factors for DVT and PTE and the magnitude of the risk, a population-based case-control study was conducted in 625 patients diagnosed as having VTE and in 625 patients without VTE from 1976 to 1990. Independent risk factors for VTE were revealed to be surgery $(\mathrm{OR}=21.7$; 95\%CI=9.4-49.9), trauma $(\mathrm{OR}=12.7 ; 95 \% \mathrm{CI}=4.1-39.7)$, cancer patients administered chemotherapy $(\mathrm{OR}=6.5$; 95\%CI $=2.1$ 20.2), and cancer patients who had not undergone chemotherapy $(\mathrm{OR}=4.1 ; 95 \% \mathrm{CI}=1.9-8.5)$. The risk of VTE in cancer patients is about four times higher than that of healthy peoples, but the risk in cancer patients receiving chemotherapy rises to more than 6 times higher (22). Because the number of patients receiving neoadjuvant chemotherapy was significantly higher in the $\mathrm{E}$ group than in the I group, the risk of perioperative VTE should be high in the E group, but enoxaparin suppressed it in the present study. 


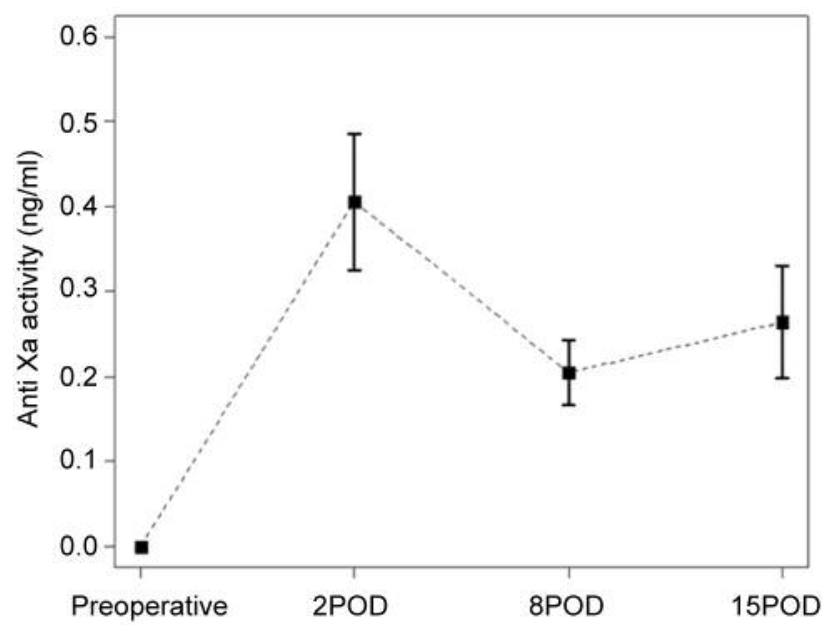

Figure 2. Postoperative change in the anti-Xa activity value.

For the limbs and cervical vein, non-invasive venous US is the first choice for diagnosis of DVT with an excellent diagnostic accuracy (27-30). A retrospective cohort study was performed on 1,140 subjects who underwent echography of the lower limbs prior to gastric cancer surgery, and 86 (7.5\%) had DVT before surgery. In the univariate analysis, the incidence of DVT was significantly higher in women, those aged $>80$ years, PS $>1$ (compared to PS=0), stage IV (compared with stages I to III), those with a preoperative chemotherapy history, and patients with central venous catheter insertion. Multiple logistic regression analysis revealed that sex, age $>80$ years, $P S \geq 1$, preoperative chemotherapy history, and central venous catheter insertion significantly correlated with preoperative DVT (31). Another study of 976 consecutive patients who underwent gastric cancer surgery and preoperative D-dimer screening showed that 176 patients were positive for D-dimer $(>1.0 \mu \mathrm{g} / \mathrm{ml})$, and $13(7.4 \%)$ were diagnosed as having DVT (32). Actually, in the present study, 5 patients $(6.9 \%)$ had thrombosis in the soleal vein before surgery.

D-dimer, which is a fibrinolytic marker, is generally used as an index for predicting thrombus formation after surgery, but D-dimer has low specificity for VTE. We can generally exclude the existence of thrombus if D-dimer is within the range of normal values. However, it is impossible to predict thrombus formation from a high D-dimer value. Actually, even in the absence of postoperative thrombus formation as in the present study, it was found that S-FMC and D-dimer values transiently increased only with severe surgical invasion. In fact, 7 patients with VTE occurring in the I group did not have a significant increase in S-FMC and Ddimer values compared with non-VTE cases in the I group (data not shown). To prevent PTE beforehand, screening with lower limb US is considered necessary after surgery.
Aggressive VTE prophylaxis, including anticoagulant drugs, is recommended for cancer patients in Europe and the United States, and even in the guidelines of the American Society of Clinical Oncology (ASCO), unless anticoagulants are contraindicated, and drug prophylaxis using heparins is recommended (25). In contrast, in the 2009 Japanese guidelines (27), major surgery for cancer in patients over 40 years old corresponds to high risk. In the perioperative period of patients undergoing such abdominal surgeries, enoxaparin, fondaparinux, or low-dose unfractionated heparin or IPC are recommended. Enoxaparin is used worldwide, and in the ninth American College of Chest Physicians guidelines published in 2012, it is positioned as one of the first-choice drugs in patients at median risk for VTE (33). Anti-coagulation therapy with IPC or enoxaparin was administered to cancer patients over 40 years old who underwent laparotomy operation of over $45 \mathrm{~min}$ in the abdominal area in a phase III trial. DVT onset was observed by venography in $19.4 \%$ in the IPC group and in $1.2 \%$ in the enoxaparin group (14). On the basis of the above-mentioned background, we conducted a phase II study examining the effectiveness and safety of enoxaparin for esophageal surgery. More specifically, we verified the hypothesis that enoxaparin would inhibit the occurrence of VTE in patients undergoing esophageal surgery, which includes the abdominal, cervical, and thoracic areas. Also, to use it safely for esophagectomy, we investigated whether anti-Xa activity would be a marker indicating the intensity of the coagulation effect. As a result, VTE was significantly suppressed in the E group. Actually, S-FMC and D-dimer values remained significantly low in the $\mathrm{E}$ group. In this group, the anticoagulant effect of enoxaparin suggested that the formation of micro-thrombus and thrombus growth were inhibited, which was considered the reason for the rate of VTE occurrence to be lower than that in the I group. In one patient in the $\mathrm{E}$ group, a change in the red color of the thoracic drainage fluid was confirmed on POD 2 after enoxaparin was administered. The fact that the anti-Xa activity was elevated at that time suggests that the intravascular volume was decreased on POD 2, which lies within the surgical invasive period, and that there was a relative increase in the blood concentration of enoxaparin.

Considering the change in anti-Xa activity, the period of 3rd-space loss on POD 2 tended to be higher than that on PODs 8 and 15. Even though renal function in the patients was normal, we thought it was important to pay attention to the bleeding and to have a proper hydration plan for the use of enoxaparin during this time. In high-risk patients, measurement of anti-Xa activity may prevent bleeding.

VTE is common in patients with cancer and is not limited to the perioperative period. Long-term daily subcutaneous LMWH has been standard treatment for such patients (11). In Japan, LMWH is not listed in health 
Table IV. Univariate analysis of preoperative risk factors for perioperative VTE in IPC group.

\begin{tabular}{|c|c|c|c|}
\hline & \multicolumn{2}{|c|}{ Incidence of VTE } & \multirow[t]{2}{*}{$p$-Value } \\
\hline & Yes $(n=7)$ & No $(n=24)$ & \\
\hline \multicolumn{4}{|c|}{ Performance Status (PS) } \\
\hline 0 & $0(0.0)$ & $6(25.0)$ & 0.450 \\
\hline 1 & $7(100.0)$ & $17(70.8)$ & \\
\hline 2 & $0(0.0)$ & $1(4.2)$ & \\
\hline \multicolumn{4}{|l|}{ Stage } \\
\hline IA & $1(14.3)$ & $10(41.7)$ & 0.159 \\
\hline IB & $0(0.0)$ & $3(12.5)$ & \\
\hline IIB & $0(0.0)$ & $3(12.5)$ & \\
\hline IIIA & $1(14.3)$ & $2(8.3)$ & \\
\hline IIIB & $1(14.3)$ & $0(0.0)$ & \\
\hline IIIC & $4(57.1)$ & $6(25.0)$ & \\
\hline \multicolumn{4}{|l|}{ COPD } \\
\hline Presence & $2(33.3)$ & $3(12.5)$ & 0.254 \\
\hline None & $4(66.7)$ & $21(87.5)$ & \\
\hline \multicolumn{4}{|l|}{ Hypertension } \\
\hline Presence & $4(57.1)$ & $13(54.2)$ & 1.000 \\
\hline None & $3(42.9)$ & $11(45.8)$ & \\
\hline \multicolumn{4}{|l|}{ Hyper lipidemia } \\
\hline Presence & $3(42.9)$ & $5(20.8)$ & 0.335 \\
\hline None & $4(57.1)$ & $19(79.2)$ & \\
\hline \multicolumn{4}{|l|}{ Hyper uricemia } \\
\hline Presence & $1(14.3)$ & $1(4.2)$ & 0.406 \\
\hline None & $6(85.7)$ & $23(95.8)$ & \\
\hline \multicolumn{4}{|l|}{ Heart disease } \\
\hline Presence & $2(28.6)$ & $2(8.3)$ & 0.212 \\
\hline None & $5(71.4)$ & $22(91.7)$ & \\
\hline \multicolumn{4}{|l|}{ Diabetes mellitus } \\
\hline Presence & $1(14.3)$ & $5(20.8)$ & 1.000 \\
\hline None & $6(85.7)$ & $19(79.2)$ & \\
\hline \multicolumn{4}{|c|}{ Cerebrovascular disease } \\
\hline Presence & $2(28.6)$ & $2(8.3)$ & 0.212 \\
\hline None & $5(71.4)$ & $22(91.7)$ & \\
\hline \multicolumn{4}{|l|}{ Operation mode } \\
\hline Open thoracotomy & $5(71.4)$ & $8(33.3)$ & 0.099 \\
\hline Thoracoscopic & $2(28.6)$ & $16(66.7)$ & \\
\hline \multicolumn{4}{|c|}{ Neoadjuvant chemotherapy } \\
\hline Presence & $5(71.4)$ & $11(45.8)$ & 0.394 \\
\hline None & $2(28.6)$ & $13(54.2)$ & \\
\hline
\end{tabular}

\begin{tabular}{|c|c|c|c|}
\hline & \multicolumn{2}{|c|}{ Incidence of VTE } & \multirow[t]{2}{*}{$p$-Value } \\
\hline & Yes $(n=7)$ & No $(n=24)$ & \\
\hline \multicolumn{4}{|l|}{ Gender } \\
\hline Male & $7(100.0)$ & $20(83.3)$ & \multirow[t]{2}{*}{0.550} \\
\hline Female & $0(0.0)$ & $4(16.7)$ & \\
\hline \multicolumn{4}{|c|}{ Body mass index } \\
\hline$<20$ & $2(28.6)$ & $10(41.7)$ & \multirow[t]{2}{*}{0.676} \\
\hline$\geq 20$ & $5(71.4)$ & $14(58.3)$ & \\
\hline \multicolumn{4}{|c|}{ Creatinine clearance (min) } \\
\hline$<90$ & $4(57.1)$ & $9(37.5)$ & \multirow[t]{2}{*}{0.413} \\
\hline$\geq 90$ & $3(42.9)$ & $15(62.5)$ & \\
\hline \multicolumn{4}{|c|}{ Operation time (min) } \\
\hline$<490$ & $2(28.6)$ & $14(58.3)$ & \multirow[t]{2}{*}{0.220} \\
\hline$\geq 490$ & $5(71.4)$ & $10(41.7)$ & \\
\hline \multicolumn{4}{|c|}{ Blood loss (g) } \\
\hline$<340$ & $2(28.6)$ & $14(58.3)$ & \multirow[t]{2}{*}{0.220} \\
\hline$\geq 340$ & $5(71.4)$ & $10(41.7)$ & \\
\hline \multicolumn{4}{|l|}{ Age } \\
\hline$<70$ & $2(28.6)$ & $17(70.8)$ & \multirow[t]{2}{*}{0.078} \\
\hline$\geq 70$ & $5(71.4)$ & $7(29.2)$ & \\
\hline \multicolumn{4}{|l|}{ APTT } \\
\hline$<28$ & $14(58.3)$ & $1(14.3)$ & \multirow[t]{2}{*}{0.083} \\
\hline$\geq 28$ & $10(41.7)$ & $6(85.7)$ & \\
\hline \multicolumn{4}{|l|}{ D-dimer } \\
\hline$<1.5$ & $15(62.5)$ & $3(42.9)$ & \multirow[t]{2}{*}{0.413} \\
\hline$\geq 1.5$ & $9(37.5)$ & $4(57.1)$ & \\
\hline \multicolumn{4}{|c|}{ Hemoglobin } \\
\hline$<12$ & $12(50.0)$ & $6(85.7)$ & \multirow[t]{2}{*}{0.191} \\
\hline$\geq 12$ & $12(50.0)$ & $1(14.3)$ & \\
\hline \multicolumn{4}{|l|}{$\mathrm{PT}(\%)$} \\
\hline$<110$ & $11(45.8)$ & $4(57.1)$ & \multirow[t]{2}{*}{0.685} \\
\hline$\geq 110$ & $13(54.2)$ & $3(42.9)$ & \\
\hline \multicolumn{4}{|l|}{ PT(sec) } \\
\hline$<12.5$ & $14(58.3)$ & $3(42.9)$ & \multirow[t]{2}{*}{0.671} \\
\hline$\geq 12.5$ & $10(41.7)$ & $4(57.1)$ & \\
\hline \multicolumn{4}{|l|}{ S-FMC } \\
\hline$<30.1$ & $12(50.0)$ & $5(71.4)$ & \multirow[t]{2}{*}{0.412} \\
\hline$\geq 30.1$ & $12(50.0)$ & $2(28.6)$ & \\
\hline
\end{tabular}

VTE: Venous thrombo-emborism; IPC: intermittent pneumatic compression; COPD: chronic obstructive pulmonary disease; PT: prothrombin time; APTT: activated partial thromboplastin time; S-FMC: soluble fibrin monomer complex.

Table V. Multivariate analysis of preoperative risk factors for perioperative VTE in IPC group.

\begin{tabular}{lcccc}
\hline & \multicolumn{2}{c}{ Multivariate analysis } & & \multicolumn{2}{c}{ Variable selection } \\
\cline { 2 - 3 } & Odds ratio $[95 \% \mathrm{CI}]$ & $p$-Value & Odds ratio [95\%CI] & $p$-Value \\
\hline Age $(\geq 70 /<70)$ & $3.850[0.483,30.700]$ & 0.203 & $4.840[0.680,34.500]$ & 0.114 \\
APTT $(\geq 28 /<28)$ & $4.980[0.443,56.100]$ & 0.194 & $6.800[0.654,70.600]$ & 0.108 \\
Operation mode & $3.440[0.438,27.000]$ & 0.24 & - & \\
\hline
\end{tabular}

VTE: Venous thrombo-emborism; IPC: intermittent pneumatic compression; APTT: activated partial thromboplastin time. Results of multivariate analysis (logistic regression analysis) using a covariate with a $p$-value less than 0.100 in univariate analysis. 
insurance reimbursement for the secondary prevention of thrombosis. For this reason, we administered direct oral anticoagulant (34) to 2 patients with DVT of the femoral veins and one patient with PTE that developed during the perioperative period following POD 15. Follow-up observation of the thrombus formed in the lower limbs of 4 patients was also conducted.

Nakamura et al. reported that heart diseases and respiratory diseases accounted for 4.6 to $6.7 \%$ of VTE cases in the Japan VTE Treatment Registry (3). Conditions such as hyperlipidemia, diabetes, and atherosclerosis have been reported as risk factors for VTE (35-37). There were no significant differences in any factors in the I group relative to whether underlying disease contributed to thrombus formation in the postoperative period.

It has been reported that PTE develops a biphasic behavior during the postoperative period. Huber et al. reported that delayed PTE is more frequent after surgery. According to their report, in the operative group, delayed embolic events occurred a median of 6 days (range $=2-25$ days) after hospital discharge and 18 days (range=6-35 days) after surgery (38). We administered enoxaparin for 14 days in the E group. No new thrombus formation was observed during the first outpatient visit at 1 month postoperatively. Therefore, administration of enoxaparin for 14 days appears to be sufficient.

In the assignment of patients to each group by the envelope method, the probability of the group sizes being 41 to 31 patients was $4.1 \%$, whereas that of the two groups being equal, 36 to 36 , was $9.24 \%$, indicating a possible significant difference. This prospective study had certain limitations. The number of cases is small, and this is a single-institution RCT. In the future, RCTs for extensive invasion of esophageal resection with enoxaparin will be necessary to confirm its efficacy and safety.

\section{Conclusion}

Our single-institution phase II RCT revealed that enoxaparin might be one of the preferable treatments to reduce the incidence of VTE in patients undergoing esophageal cancer surgery. It should be further evaluated in future multiinstitutional RCTs.

\section{Conflicts of Interest}

Dr. Yoshida reports receipt of grants, personal fees and non-financial support from EA Pharma Co., Ltd., Sanofi, Yakult Honsha Co., Ltd., Chugai Pharm. Co., Ltd., Taiho Pharm. Co., Ltd., Takeda Pharm. Co., Ltd., Eli Lilly Japan K.K., Daiichi Sankyo Co., Ltd., Ono Pharm. Co., Ltd., Merck Serono Co., Ltd., and Novartis Pharma K.K.; and grants from Kyowa Hakko Kirin Co., Ltd. outside of the submitted work. Dr. Tanaka reports receipt of grants from Daiichi Sankyo Co., Ltd. outside of the submitted work.

\section{Authors' Contributions}

YT conceived the study and planned the study design as the principal investigator. YT interpreted the results and wrote the manuscript draft. KY revised the manuscript draft by adding intellectual insights and provided critical advice. AY, SH, HT, TS, $\mathrm{NM}$, and KY obtained the data and provided their critical comments to improve the manuscript. TS is a specialist in medical statistical analysis and was in charge of data analysis of this study. All authors gave approval of the final version for submission.

\section{Acknowledgements}

The Authors would like to thank Rise Japan for providing editorial assistance and TS for analyzing the data.

\section{References}

1 Khorana AA, Francis CW, Culakova E, Kuderer NM and Lyman GH: Thromboembolism is a leading cause of death in cancer patients receiving outpatient chemotherapy. J Thromb Haemost 5: 632-634, 2007. PMID: 17319909. DOI: 10.1111/j.15387836.2007.02374.x

2 Varki A: Trousseau's syndrome: multiple definitions and multiple mechanisms. Blood 110: 1723-1729, 2007. PMID: 17496204. DOI: 10.1182/blood-2006-10-053736

3 Nakamura M, Miyata T, Ozeki Y, Takayama M, Komori K, Yamada N, Origasa H, Satokawa H, Maeda H, Tanabe N, Unno N, Shibuya T, Tanemoto K, Kondo K and Kojima T: Current venous thromboembolism management and outcomes in Japan. Circ J 78: 708-717, 2014. PMID: 24401573.

4 Hansrani V, Khanbhai M and McCollum C: The prevention of venous thromboembolism in surgical patients. Adv Exp Med Biol 906: 1-8, 2017. PMID: 27620304. DOI: 10.1007/55842016-100

5 Mantziari S, Gronnier C, Pasquer A, Gagnière J, Théreaux J, Demartines N, Schäfer M and Mariette C: FREGAT Working Group-FRENCH-AFC: Incidence and risk factors related to symptomatic venous thromboembolic events after esophagectomy for cancer. Ann Thorac Surg 102: 979-984, 2016. PMID: 27262916. DOI: 10.1016/j.athoracsur.2016.03.093

6 Parry K, Sadeghi AH, van der Horst S, Westerink J, Ruurda JP and van Hillegersberg R: Intermittent pneumatic compression in combination with low-molecular weight heparin in the prevention of venous thromboembolic events in esophageal cancer surgery. J Surg Oncol 115: 181-185, 2017. PMID: 28054341. DOI: $10.1002 /$ jso. 24480

7 Kato F, Takeuchi H, Matsuda S, Kawakubo H, Omori T and Kitagawa Y: Incidence of and risk factors for venous thromboembolism during surgical treatment for esophageal cancer: a single-institution study. Surg Today 46: 445-452, 2016. PMID: 26094966. DOI: 10.1007/s00595-015-1196-1

8 Bellini G, Teng A, Kotecha N, Sutton E, Yang CK, Passeri M, Lee DY and Rose K: The identification of risk factors for venous thromboembolism in gastrointestinal oncologic surgery. J Surg Res 205: 279-285, 2016. PMID: 27664873. DOI: 10.1016/j.jss. 2016.06.089

9 Yoshida N, Baba Y, Miyamoto Y, Iwatsuki M, Hiyoshi Y, Ishimoto T, Imamura $\mathrm{Y}$, Watanabe $\mathrm{M}$ and Baba $\mathrm{H}$ : Prophylaxis 
of postoperative venous thromboembolism using enoxaparin after esophagectomy: a prospective observational study of effectiveness and safety. Ann Surg Oncol 25: 2434-2440, 2018. PMID: 29876696. DOI: 10.1245/s10434-018-6552-0

10 Gould MK, Garcia DA, Wren SM, Karanicolas PJ, Arcelus JI, Heit JA and Samama CM: Prevention of VTE in nonorthopedic surgical patients antithrombotic therapy and prevention of thrombosis, 9th ed: American College of Chest Physicians Evidence Based Clinical Practice Guidelines. Chest 141: 227277, 2012. PMID: 22315263. DOI: 10.1378/chest.11-2297

11 Lee AY, Levine MN, Baker RI, Bowden C, Kakkar AK, Prins M, Rickles FR, Julian JA, Haley S, Kovacs MJ and Gent M: Randomized comparison of low-molecular-weight heparin versus oral anticoagulant therapy for the prevention of recurrent venous thromboembolism in patients with cancer (CLOT) investigators. Low-molecular-weight heparin versus a coumarin for the prevention of recurrent venous thromboembolism in patients with cancer. N Engl J Med 349: 146-153, 2003. PMID: 12853587. DOI: $10.1056 /$ NEJMoa025313

12 Cimminiello C, Prandoni P, Agnelli G, Di Minno G, Polo Friz H, Scaglione F, Boracchi $\mathrm{P}$, Marano $\mathrm{G}$ and Harenberg $\mathrm{J}$ : Thromboprophylaxis with enoxaparin and direct oral anticoagulants in major orthopedic surgery and acutely ill medical patients: A metaanalysis. Intern Emerg Med 12: 1291-1305, 2017. PMID: 28756546. DOI: 10.1007/s11739-017-1714-9

13 Nagata C, Tanabe H, Takakura S, Narui C, Saito M, Yanaihara $\mathrm{N}$ and Okamoto A: Randomized controlled trial of enoxaparin versus intermittent pneumatic compression for venous thromboembolism prevention in Japanese surgical patients with gynecologic malignancy. J Obstet Gynaecol Res 41: 1440-1448, 2015. PMID: 26111609. DOI: $10.1111 /$ jog. 12740

14 Sakon M, Kobayashi T and Shimazui T: Efficacy and safety of enoxaparin in Japanese patients undergoing curative abdominal or pelvic cancer surgery: results from a multicenter, randomized, open-label study. Thromb Res 125: 65-70, 2010. PMID: 19919878. DOI: 10.1016/j.thromres.2009.09.009

15 Sobin LH, Gospodarowicz MK and Wittekind C: International Union Against Cancer. TNM Classification of Malignant Tumors. 7th ed. Chichester: Wiley-Blackwell, 2010.

16 National Cancer Institute. National Cancer Institute Common Terminology Criteria for Adverse Events v 4.0. Bethesda: National Cancer Institute, May 28, 2009.

17 Sakon M, Maehara Y, Yoshikawa $\mathrm{H}$ and Akaza H: Incidence of venous thromboembolism following major abdominal surgery: a multi-center, prospective epidemiological study in Japan. J Thromb Haemost 4: 581-586, 2006. PMID: 16460440. DOI: 10.1111/j.1538-7836.2006.01786.x

18 Hammond J, Kozma C, Hart JC, Nigam S, Daskiran M, Paris A and Mackowiak JI: Rates of venous thromboembolism among patients with major surgery for cancer. Ann Surg Oncol 18: 32403247, 2011. PMID: 21584837. DOI: 10.1245/s10434-011-1723-2

19 Mismetti P, Laporte S, Darmon JY, Buchmüller A and Decousus $\mathrm{H}$ : Meta-analysis of low molecular weight heparin in the prevention of venous thromboembolism in general surgery. Br J Surg 88: 913-930, 2001. PMID: 11442521. DOI: 10.1046/ j.0007-1323.2001.01800.x

20 Kojima A, Yoshida K, Kurita O, Manabe T, Hino K, Shibuya K, Yamaguchi T, Saitou H, Yamashita I and Nomura N: Investigation of time-course changes in the incidence of deep vein thrombosis during the perioperative period of cancer of the digestive system: a prospective study from our institution. J Jpn Coll Angiol 53: 143-149, 2013.

21 Walker AJ, Card TR, West J, Crooks C and Grainge MJ: Incidence of venous thromboembolism in patients with cancer a cohort study using linked United Kingdom databases. Eur J Cancer 49: 1404-1413, 2013. PMID: 23146958. DOI: 10.1016/ j.ejca.2012.10.021

22 Heit JA, Silverstein MD, Mohr DN, Petterson TM, O'Fallon WM and Melton LJ 3rd: Risk factors for deep vein thrombosis and pulmonary embolism: a population-based case-control study. Arch Intern Med 160: 809-815, 2000. PMID: 10737280.

23 Blom JW, Doggen CJ, Osanto $S$ and Rosendaal FR: Malignancies, prothrombotic mutations, and the risk of venous thrombosis. JAMA 293: 715-722, 2005. PMID: 15701913. DOI: 10.1001/jama.293.6.715

24 Gallus AS: Prevention of post-operative deep leg vein thrombosis in patients with cancer. Thrombo Haemost 78: 126132, 1997. PMID: 9198141.

25 Lyman GH, Khorana AA, Falanga A, Clarke-Pearson D, Flowers C, Jahanzeb M, Kakkar A, Kuderer NM, Levine MN, Liebman H, Mendelson D, Raskob G, Somerfield MR, Thodiyil P, Trent D and Francis CW: American Society of Clinical Oncology. American Society of Clinical Oncology guideline: recommendations for venous thromboembolism prophylaxis and treatment in patients with cancer. J Clin Oncol 25: 5490-5505, 2007. PMID: 17968019. DOI: 10.1200/JCO.2007.14.1283

26 Agnelli G, Bolis G, Capussotti L, Scarpa RM, Tonelli F, Bonizzoni E, Moia M, Parazzini F, Rossi R, Sonaglia F, Valarani B, Bianchini C and Gussoni G: A clinical outcome-based prospective study on venous thromboembolism after cancer surgery: the @RISTOS project. Ann Surg 243: 89-95, 2006. PMID: 16371741.

27 JCS Joint Working Group: Guidelines for the diagnosis, treatment and prevention of pulmonary thromboembolism and deep vein thrombosis (JCS 2009). Circ J 75: 1258-1281, 2011. PMID: 21441695.

28 Ohgi S, Ito K, Tanaka K, Hara H and Mori T: Echogenic types of venous thrombi in the common femoral vein by ultrasonic Bmode imaging. Vasc Endovascular Surg 25: 253-258, 1991.

29 Yamaki T, Nozaki M, Sakurai H, Takeuchi M, Soejima K and Kono T: Prospective evaluation of a screening protocol to exclude deep vein thrombosis on the basis of a combination of quantitative D-dimer testing and pretest clinical probability score. J Am Coll Surg 201: 701-709, 2005. PMID: 16256912. DOI: 10.1016/j.jamcollsurg.2005.06.267

30 Bates SM, Jaeschke R, Stevens SM, Goodacre S, Wells PS, Stevenson MD, Kearon C, Schunemann HJ, Crowther M, Pauker SG, Makdissi R and Guyatt GH: Diagnostic of DVT: Antithrombotic therapy and prevention of thrombosis, 9th ed: American College of chest physicians evidence-based clinical practice guidelines. Chest 141: 351-418, 2012. PMID: 22315267. DOI: $10.1378 /$ chest.11-2299

31 Tanizawa Y, Bando E, Kawamura T, Tokunaga M, Makuuchi R, Iida K, Nanri K, Yoneyama M and Terashima M: Prevalence of deep venous thrombosis detected by ultrasonography before surgery in patients with gastric cancer: a retrospective study of 1140 consecutive patients. Gastric Cancer 20: 878-86, 2017. PMID: 27987041. DOI: 10.1007/s10120-016-0677-2

32 Wada T, Fujiwara H, Morita S, Fukagawa $\mathrm{T}$ and Katai H: Incidence of and risk factors for preoperative deep venous 
thrombosis in patients undergoing gastric cancer surgery. Gastric Cancer 20: 872-877, 2017. PMID: 28120128. DOI: 10.1007/ s10120-017-0690-0

33 Gould MK, Garcia DA, Wren SM, Karanicolas PJ, Arcelus JI, Heit JA and Samama CM: Prevention of VTE in nonorthopedic surgical Patients: antithrombotic therapy and prevention of thrombosis, 9th ed: American College of Chest Physicians evidence-based clinical practice guidelines. Chest 141: 227-277, 2012. PMID: 22315263. DOI: 10.1378/chest.11-2297

34 Tritschler T, Kraaijpoel N, Le Gal G and Wells PS: Venous thromboembolism: advances in diagnosis and treatment. JAMA 320: 1583-1594, 2018. PMID: 30326130. DOI: 10.1001 /jama. 2018.14346

35 Kawasaki T, Kambayashi J and Sakon M: Hyperlipidemia: a novel etiologic factor in deep vein thrombosis. Thromb Res 79: 147-151, 1995. PMID: 7676401.
36 Gariani K, Mavrakanas T, Combescure C, Perrier A and Marti $\mathrm{C}$ : Is diabetes mellitus a risk factor for venous thromboembolism? A systemic review and meta-analysis of case-control and cohort studies. Eur J Intern Med 28: 52-58, 2016. PMID: 26507303. DOI: 10.1016/j.ejim.2015.10.001

37 Mi Y, Yan S, Lu Y, Liang Y and Li C: Venous thromboembolism has the same risk factors as atherosclerosis: A PRISMA-compliant systemic review and meta-analysis. Medicine (Baltimore) 95: 4495, 2016. PMID: 27512866. DOI: 10.1097/ MD.0000000000004495

38 Huber O, Bounameaux H, Borst F and Rohner A: Postoperative pulmonary embolism after hospital discharge. An underestimated risk. Arch Surg 127: 310-313, 1992. PMID: 1550477.

Received March 12, 2019

Revised March 27, 2019

Accepted March 29, 2019 